\title{
Correction to: Smart Government E-Services for Indian Railways Using Twitter
}

\author{
Mukta Goyal, Namita Gupta, Ajay Jain and Deepa Kumari
}

\section{Correction to:}

Chapter "Smart Government E-Services for Indian

Railways Using Twitter" in: D. K. Sharma et al. (eds.),

Micro-Electronics and Telecommunication Engineering,

Lecture Notes in Networks and Systems 106, https://doi.org/10.1007/978-981-15-2329-8_73

In the original version of the book, in Chapter 73, Figure 1 is replaced with a revised figure as given below and the heading of Section 2.2 "Micro Post Enrichment Algorithm" is now replaced with the heading "Extraction of Tweets". The chapter and book have been updated with the change.

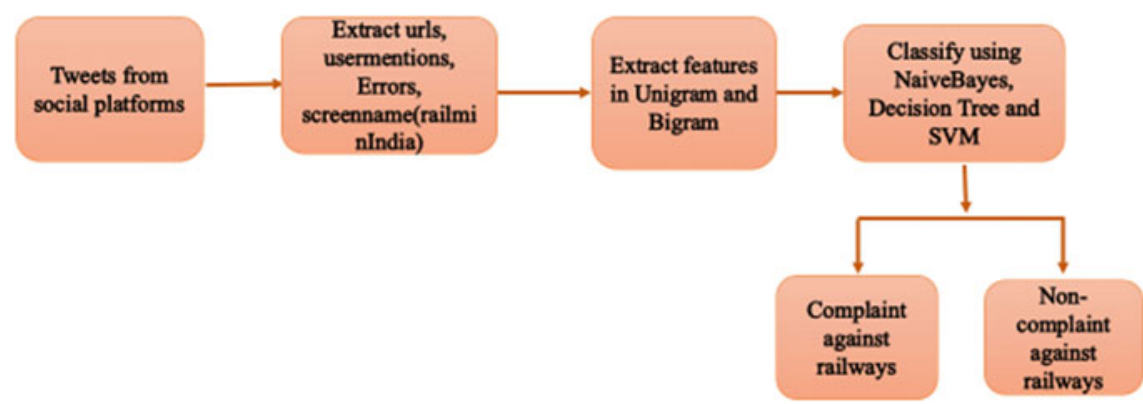

Fig. 1 Architecture for Smart E-governance

The updated version of this chapter can be found at https://doi.org/10.1007/978-981-15-2329-8_73 